\title{
Migration: The aftershocks to the provision of healthcare
}

\author{
Stephan Lobitz \\ Amsterdam Street Children's Hospital, Cologne, Germany
}

Migration is the "movement of people to a new area or country in order to find work or better living conditions" (Oxford dictionary). The term "migration" summarizes forced, reluctant and voluntary migration. Voluntary migration is a comparatively constant event. But reluctant and, in particular, forced migration have been subject to substantial change during the last years. At the end of 2016, more than 17.2 million refugees ( +5.3 million Palestinians) were on the run outside their home countries. $55 \%$ of them fled from Syria (5.5 million), Afghanistan (2.5 million) and South Sudan (1.4 million), respectively. The top hosting countries were not, in fact, the Southern and Western European or North American, but some of the poorest countries in the world. With the refugees from countries where disorders of haemoglobin are very prevalent, the number of patients in the host countries significantly increased within a very short period of time. The extraordinary circumstances required rapid rethinking and adaption and, therefore, did not only pose a big challenge but, in some countries, also a big chance to improve care for patients suffering from hemoglobinopathies.

Although there are certainly several trouble spots in the world, the Middle East crisis was and still is currently the most prominent one. There is a significant prevalence of thalassemia and sickle cell disease among the Syrian and Iraqi population and since the chronically ill were presumably those who left their home countries first, there was a dramatic increase in the prevalence of thalassaemia and sickle cell disease in the host countries. Many patients fled to Western and Northern European countries where hemoglobinopathies were very rare and where the healthcare systems were unable to cope with this sudden increase in patient numbers and complications. For example, disease characteristics were much more pronounced than doctors were used to. Complications occurred that physicians only knew from textbooks. In addition, virtually all families needed significant help in psychosocial matters and many refugees were severely traumatized.

\section{Methods}

In addition to an extensive review of the literature, international experts for haemoglobin disorders were contacted via email and asked to take part in an online survey. They were asked if and how relevant migration is for their clinical practise, if they did observe changes in the number of patients during the last five years and if and how they responded to these changes.

\section{Results}

The results of this survey are pending and will be presented and discussed at the TIF conference.
Correspondence: Stephan Lobitz, Amsterdam Street Children's Hospital, Cologne, Germany

This work is licensed under a Creative Commons Attribution 4.0 License (by-nc 4.0).

(C) Copyright S. Lobitz, 2018

Licensee PAGEPress, Italy

Thalassemia Reports 2018; 8:7471

doi:10.4081/thal.2018.7471 